\title{
Thinking differently, together: Towards a lifelong learning society
}

\section{Paul Stanistreet $^{1}$}

Published online: 4 September 2020

(c) UNESCO Institute for Lifelong Learning and Springer Nature B.V. 2020

It has become a cliché to say we are living through unprecedented times. The COVID-19 pandemic has unleashed a crisis that has not only exposed deep and entrenched inequalities, both within and between societies, but has also demonstrated how profoundly interconnected we all are. How well we recover from or learn to live with COVID-19 will depend, to a large extent, on how willing people are to behave in a cooperative way, acknowledging and respecting the needs of their neighbours as well as their own. This is as true among nations as it is among people. One of the many lessons of the pandemic, highlighted in the final article of this issue of the International Review of Education - Journal of Lifelong Learning (IRE), is how intimately and inescapably individual behaviour and group risk are linked. The worst public health crisis in living memory is an appalling tragedy; but it is also an opportunity - a fleeting one, I suspect - to restore and strengthen our commitment to the common good, address long-standing structural inequalities (and question the privileges of the very wealthy), and radically rethink areas of social policy, including education, in terms of public rather than private good. Old orthodoxies must fall by the wayside if we are to build a future that is fair, safe, inclusive and sustainable.

The pandemic has confined people to their homes, deprived some workers of a livelihood (while exposing others and their families to acute risk), shut businesses (in some cases permanently) and forced schools, universities and other education providers to close their doors and seek alternative ways of ensuring continuity of learning. The crisis is presenting enormous challenges in education. New questions are being asked of educators and education policymakers, and they are being asked in every part of the world and at every level of education. Not surprisingly, this crisis has also prompted a major revaluation of what education is for and how fairly its benefits are distributed, and a serious re-examination of whether national systems of education, as they are currently constituted (and funded), can deliver on their increasingly tired-looking promises to alleviate poverty and inequality. With the social contract looking fragile in many parts of the world, and the cost of the

Paul Stanistreet

p.stanistreet@unesco.org

1 UNESCO Institute for Lifelong Learning, Hamburg, Germany 
pandemic being paid disproportionately by those with the least resources, and particularly people in low-paid and precarious employment, it is surely timely to ask what kind of society we want to live in and how education can help get us there.

Of course, COVID-19 is not the only, or perhaps even the most significant, challenge we face globally. The climate crisis looms large (July 2019 to June 2020 were the hottest 12 months on record, Masters 2020), ${ }^{1}$ while societies around the world struggle to adapt to the new technologies that are transforming workplaces and to respond to the growth in populist politics that is threatening democratic values in some parts of the world. Large-scale movements in population, demographic change, and the hundreds of millions of people worldwide who lack basic skills are also demanding responses from our education systems and obliging us to reconsider the values that underpin them. All of these challenges, in one way or another, point to a need for lifelong learning; not just the promise of continuing access to vocational training (the skills dimension of lifelong learning), but the kind of holistic vision of learning throughout life set out by Edgar Faure and Jacques Delors in their seminal (but, in policy terms, largely ignored) reports for UNESCO (Faure et al. 1972; Delors et al. 1996). ${ }^{2}$ Adapting to climate change, sorting truth from disinformation, learning to live with difference, and being prepared to continue learning, particularly in the context of new technology and the changing workplace, demand citizens who are not merely job-ready but also thoughtful, resilient, creative, tolerant, cooperative, civically engaged and capable of critical thinking.

Yet while we have known about most of these challenges for decades, such a vision of lifelong learning remains, in all but a few exceptional places, a distant prospect. Many places are headed in the opposite direction, narrowing the curriculum to focus more closely on employability and vocational skills, cutting courses in the arts and humanities (or actively discouraging people from taking them), and reducing adults' opportunities to learn, meet in shared spaces such as libraries and community centres, or engage in the civic life of their communities. If lifelong learning is to play its full part in recovery and in securing a post-COVID world that is fair, inclusive and worth living in, for everyone and not just the privileged few, we have to start doing things differently. UNESCO's Futures of Education initiative, ${ }^{3}$ very much the successor to the commissions that produced the Faure and Delors reports, offers the prospect of radical new thinking and a mandate for progressive change, but it is to be hoped that it does not meet the fate of its predecessors as yet another

\footnotetext{
1 Masters, J. (2020). June 2020: Earth's third-warmest June on record. Yale Climate Connections, Eye on the Storm, 13 July [blogpost]. Retrieved 25 August 2020 from https://yaleclimateconnectio ns.org/2020/07/june-2020-earths-third-warmest-june-on-record/

${ }^{2}$ Faure, E., Herrera, F., Kaddoura, A. R., Lopes, H., Petrovsky, A. V., Rahnema, M. \& Ward, F. C. (1972). Learning to be: The world of education today and tomorrow. Paris: UNESCO/Harrap. Retrieved 25 August 2020 from https://unesdoc.unesco.org/ark:/48223/pf0000001801.

Delors, J., et al. (1996). Learning: The treasure within. Report to UNESCO of the International Commission on Education for the Twenty-first century. Paris: UNESCO.

3 UNESCO's Futures of Education initiative, led by a dedicated International Commission, is a global initiative to reimagine how knowledge and learning can shape the future of humanity and the planet. For more information, visit https://en.unesco.org/futuresofeducation/ [accessed 25 August 2020].
} 
unrealised inspiration to a field that continues to push against rather than with the general direction of education policy.

This issue of IRE considers lifelong learning in all its manifold dimensions, from primary and secondary school to higher education, adult continuing education, non-formal adult education and prison education, in the context of the Sustainable Development Goals and other critical global challenges, including the COVID-19 pandemic. It highlights some of the challenges we face while also pointing hopefully to future prospects. Above all, perhaps, it calls on everyone involved in education not only to think differently but to think together.

The first article, "Introducing a tool to gauge curriculum quality under Sustainable Development Goal 4: The case of primary schools in Vietnam", by Anh-Duc Hoang, Hiep-Hung Pham, Yen-Chi Nguyen, Le-Kim-Ngan Nguyen, Quan-Hoang Vuong, Minh Q. Dam, Trung Tran and Tien-Trung Nguyen, considers what makes a quality curriculum, from the perspective of the fourth Sustainable Development Goal (SDG 4), which focuses on education. The article presents an instrument used to evaluate the quality of curricula in a sample of private primary schools in Vietnam. The researchers chose private schools because, in Vietnam, they have greater license to customise their curriculum than state schools and can therefore provide a useful model for policymakers, school leaders and teachers seeking to improve quality in state schools. The authors adapted a curriculum evaluation framework developed by Philip Stabback on behalf of the UNESCO International Bureau of Education (IBE) in the context of achieving the SDG 4 targets in Vietnam, and piloted the customised tool in the four schools. They introduced a scaled qualitative curriculum evaluation rubric to create a tool capable of developing, evaluating and continuously improving the curriculum in Vietnam. A more comprehensive system, they suggest, could enable the government to measure the adjustment of state schools to educational reforms. The model, they conclude, could also serve as "a foundation for establishing a mixed-methods ranking system for evaluating K-12 schools' sustainable development overall". As we approach the midway point in the United Nations 2030 Agenda for Sustainable Development, this is perhaps a model other countries will want to adapt in developing their own curriculum assessment formula, adjusted both to local context and the SDG 4 targets.

Formal school education is an important factor in achieving the SDGs, but nonformal learning is important too, particularly in developing some of the important skills of communication, resilience and creativity implicit in the notion of a lifelong learning society and significant in the cultivation of good academic performance. Some of these themes are explored by Azar Abizada, Ulkar Gurbanova, Ainura Iskandarova and Narmin Nadirzada in their article "The effect of extracurricular activities on academic performance in secondary school: The case of Azerbaijan". The article analyses the effect (positive and negative) of extracurricular activities on state secondary school students' academic performance in Azerbaijan. The authors focus on three groups of extracurricular activities: sports, fine arts (drama, music and dance) and student clubs. For data on academic performance, they use the results of a centralised state school examination which assesses students in two subjects: language of instruction (either Azerbaijani or Russian) and mathematics. The study found that some extracurricular activities appear to have a positive effect 
on students' academic performance, while others have little or no effect and, even, in one case, a negative effect. While there was no evident effect on academic performance in mathematics as a result of taking part in sports activities, there seemed to be a negative impact on language results. Meanwhile, students who took part in fine arts activities performed significantly better in the language exam that those who did not (there was no significant difference in maths, though performance in maths did improve as the number of extracurricular fine arts activities increased), and students who participated in school clubs did significantly better that students who did not in both language and mathematics. With regard to the latter, an increase in the number of clubs to which a student belongs also correlates with better language and maths results. The study indicates that while extracurricular activity is clearly relevant to academic performance and has a generally very positive impact, the effects are more complex than might be supposed.

The clubs students belong to, their extracurricular interests, their social networks and family backgrounds are among the factors that can influence their choice of university and how well they are able to make the transition to higher study. These choices are the subject of the article "Functions of an institutional culture of access: Student choices and transitions to university in South Africa", by Nelson Masanche Nkhoma. Although a range of factors influence a student's choice of university, including academic entry requirements, acceptance into a programme, sufficient funding, tips from family and friends, and institutional marketing, the author foregrounds, in particular, the concept of institutional culture. This refers to a university's practices, norms and values which are "collectively shared by the members of the institution, shaping the way in which people interact and work together within the institution and how they present it and themselves to the outside world". The article presents a case study investigating the role of institutional culture in promoting access to the state-funded university system in South Africa. Drawing on empirical data gathered from staff and first-year students, and with Ali Mazrui's "seven functions of culture" in mind (Mazrui 1997), ${ }^{4}$ the author argues that students' university choice and aspirations are mainly influenced by three functions of culture: the way in which university practices are communicated and the level of awareness (communication); institutional incentives and disincentives, including financial support (or its absence) and proximity to family home (motivation); and aspects of institutional identity. Students indicated that the identity of an institution was important in choosing their university, noting that family or school associations with a particular university, or the institution's links to a profession, were important factors influencing their own sense of identification. Students from poorer backgrounds have to contend with greater costs in reconfiguring their identity to "affiliate with a university", the study notes. This can be a significant barrier to poorer students applying to prestigious institutions. Enabling fairer access, the author suggests, could be achieved, in part, through a more nuanced inclusion of other cultural functions in institutional culture,

\footnotetext{
4 Mazrui, A.A. (1997). The muse of modernity and the quest for development. In P.G. Altbach, \& S.M. Hassan (Eds), The muse of modernity: Essays on culture as development in Africa (pp. 1-18). Trenton, NJ: Africa World Press.
} 
for example, by emphasising different pathways to higher education, stressing the importance of lifelong learning and drawing attention to different types of learning outcome.

Students from disadvantaged backgrounds face substantial barriers in accessing higher education. They are also much more likely to struggle to adapt to higher study and to drop out once they are there. This is particularly the case with adult students, among whom dropout is especially common. Understanding how adult students learn is therefore a valuable endeavour. "Exploring the dominant learning styles of adult learners in higher education", by Samuel Amponsah, aims to establish the characteristics and dominant "learning styles" of adults enrolled in a diploma programme at an institution of higher education in Ghana. The study focuses on 21 students (10 female, 11 male) over the age of 25 who took part in a survey (using Peter Honey and Alan Mumford's learning styles questionnaire, Honey and Mumford 1986) ${ }^{5}$ and in focus groups interviews. The author found three of four learning styles to be dominant among the sample group: pragmatist ("curious and problemsolving-oriented learners"), reflector ("critically cautious observers") and theorist ("logical and analytical learners"). Another notable finding was the absence of the fourth learning style among participants, namely activist (learners who operate in the "here and now" and prefer learning by doing), the reason for which the author proposes could be due to a reluctance among mature students "to be in the limelight, a key attribute of activists". Understanding the learning styles of adult students may, he argues, help teachers and institutions improve their performance and make higher education more enjoyable for adults. Certainly, listening to adults and understanding their preferences should play a major part in designing courses and is an important dimension of creating an enabling environment for adults, though, as the author thoughtfully notes, both context and learning style are subject to change, as is selfperception, and appropriate weighting needs to be given too to these factors.

In working with disadvantaged or hard-to-reach students it is important that educators understand what influences their motivation to learn. This is the subject matter of 'Prisoners' academic motivation, viewed from the perspective of self-determination theory: Evidence from a population of Norwegian prisoners", by Terje Manger, Jørn Hetland, Lise Øen Jones, Ole Johan Eikeland and Arve Asbjørnsen. While in a previous article in IRE the authors considered prisoners' perceived barriers to participation in education (Manger et al. 2019), ${ }^{6}$ in this complementary article they explore prisoners' academic motivation structure from the theoretical perspective of self-determination theory, using the Academic Motivation Scale (Vallerand et al. 1989; Ratelle et al. 2007). ${ }^{7}$ They analysed survey responses from 529 prisoners (29

\footnotetext{
${ }^{5}$ Honey, P., \& Mumford, A. (1986). The manual of learning styles. Maidenhead: Ardingly House.

${ }^{6}$ Manger, T., Eikeland, O.J., \& Asbjørnsen, A. (2019). Why do not more prisoners participate in adult education? An analysis of barriers to education in Norwegian prisons. International Review of Education, 65(5), 711-733. https://doi.org/10.1007/s11159-018-9724-z.

7 Vallerand, R.J., Blais, M.R., Brière, N.M., \& Pelletier, L.G. (1989). Construction et validation de l'Échelle de Motivation en Éducation (EME) [On the construction and validation of (the French form of) the academic motivation scale]. Canadian Journal of Behavioural Science, 21(3), 323-349. https://doi. org/10.1037/h0079855.
}

Ratelle, C.F., Guay, F., Vallerand, R.J., Larose, S., \& Senécal, C. (2007). Autonomous, controlled, and 
female, 500 male) with Norwegian citizenship who participated in education while incarcerated, investigating how prison students' motivation might be summarised to a smaller set of factors than other studies propose. A confirmatory factor analysis suggested that a five-factor model yielded the best fit with the data provided by the prisoners. This included: intrinsic motivation (for the satisfaction of the engagement itself); three types of extrinsic motivation (namely identified regulation [because they accept the utility of a behaviour], introjected regulation [to feel pride or avoid guilt or disapproval] and external regulation [to gain reward or avoid punishment]) and amotivation ("without any motivation"). An alternative three-factor model created by collapsing the three extrinsic dimensions into a single dimension was found to fit the data significantly less well. The researchers' structural model revealed that younger prisoners displayed more controlled academic motivations than older ones, who displayed more autonomous motivations. Perhaps more surprisingly, and contrary to the authors' expectations, prisoners with a higher level of education did not display more autonomous academic motivations than those with a lower level.

The final article of this issue considers adult learning and education (ALE) in the context of the COVID-19 pandemic. "Adult learning and education as a tool to contain pandemics: The COVID-19 experience", by Henrique Lopes and Veronica McKay, begins by highlighting the importance of changing people's attitudes and behaviour in reducing numbers of new infections and, thus, combating the pandemic. National responses to the pandemic cannot focus simply on adjustments to the health system, the authors argue, but must instead "be conceptualised as the organic response of a country's entire society and all social institutions in which citizens are active participants". Getting citizens to adopt appropriate behaviours requires their having a level of prior education sufficient both to understand the risk level and to make informed health-related decisions on the basis of the information available. ALE, therefore, has a key role to play, particularly in countries with large numbers of low-literate adults, where healthcare systems are often also fragile. Studies show that people with low levels of literacy are less responsive to health education, less likely to use disease prevention services, and less likely to successfully manage chronic disease than literate citizens. There is therefore a significant challenge in realising health literacy benefits for all. The authors draw hope from an evaluation of a large-scale adult literacy campaign launched in South Africa in 2008 which yielded measurable outcomes and proved that the intervention had enabled adults to better understand health messages. This indicates that ALE has a critical function in ensuring that all adults are prepared for crises such as the one we are experiencing right now, and that no one is left behind when it comes to health literacy, particularly those failed by their respective school system.

The article demonstrates the important role of adult education not only in current efforts to control the pandemic but also in preparing the global community for possible future crises. The authors argue that ALE should be understood as a vital part

Footnote 7 (continued)

amotivated types of academic motivation: A person-oriented analysis. Journal of Educational Psychology, 99(4), 734-746. https://doi.org/10.1037/0022-0663.99.4.734. 
of every national emergency strategy, both in terms of prior planning for possible future emergencies (such as earthquakes, tornados, flooding and bushfires), and in terms of reacting to emergencies such as the current COVID-19 pandemic as and when they occur. This points to a wider need to realise the rich potential contribution of ALE to different agendas, and to join up our thinking about education, connecting the dots not only between education and health, but also between education and active citizenship, social cohesion and efforts to address the climate crisis, for example. Such a rethinking of the purposes and reach of education is long overdue. While the current crisis makes us, quite naturally, long for things to return to normal, it also tells us that this longed-for return to life as it used to be is not really possible or even, perhaps, desirable; not if we are to create a world in which the suffering of the poor and vulnerable does not play out again and again, in evermore predictable ways, while the rest of us wring our hands and ask how this could happen. However we emerge from the crisis, the challenge is clear: do we cling to the same old failed and flawed ideas, tolerating the social and economic inequalities amplified by the pandemic and writing off the life changes of hundreds of millions of people, or do we raise our sights to the kind of society we really need; one in which learning for all sorts of purposes, throughout and across life, is available to everyone in ways that work for them and their communities and match their needs and aspirations? If we are serious about achieving a more equal, prosperous, healthy and peaceful future, we need to start building it now.

Publisher's Note Springer Nature remains neutral with regard to jurisdictional claims in published maps and institutional affiliations. 